\title{
Designing Convivial Digital Cities: A Social Intelligence Design Approach
}

\author{
Patrice Caire \\ *Dept. of Computer Science and Communication, Luxembourg University \\ 6, Rue Richard Coudenhove-Kalergi \\ L-1359 Luxembourg City, LUXEMBOURG \\ patrice.caire@uni.lu
}

\begin{abstract}
Conviviality is a mechanism to reinforce social cohesion and a tool to reduce mis-coordination between individuals, groups and institutions in web communities, for example in digital cities. We use a two-fold definition of conviviality as a condition for social interactions and an instrument for the internal regulation of social systems. In this paper we discuss the use of social intelligence design to model conviviality for digital cities, by first contrasting commercial with public digital cities, ergonomics with intelligent agents and then, social norms for conviviality with legal and institutional norms in digital cities. We show the role of the distinction among various kinds of use of conviviality, the positive aspects of conviviality and the negative aspects that emergent when conviviality becomes the instrument of power relations or in the absence of conviviality.
\end{abstract}

Keywords: Conviviality, multi-agent systems, normative systems, social intelligence design, ergonomics and human factors, digital cities.

\section{INTRODUCTION}

The role of norms for conviviality is a condition for social interactions and an instrument for the internal regulation of social systems (Caire, 2007b). For example, in digital cities "government regulations extend laws with specific guidance to corporate and public actions" (Lau et al., 2005). One view of social intelligence is that it may be "attributed to a collection of actors/agents and defined as an ability to manage complexity and learn from experiences as a function of the design of social structure. This view emphasizes the role of social conventions that constrain the way individual agents interact with each other" (Fruchter et al., 2005).

In this paper we raise the following question: How can social intelligence design be used to model conviviality? We approach this question focusing on conviviality in digital cities, by first contrasting public with commercial digital cities, then ergonomics with intelligent systems and, finally, norms for conviviality with legal and institutional norms in digital cities.

Our main question breaks down into the following research questions: (1)What is a digital city as far as social intelligence design is concerned? From social intelligence design point of view, there seems to be a distinction between public and commercial websites. Indeed, social intelligence design main themes are about using new technologies to "mediate human communication and collaboration across geographical and cultural divides" and to enhance the relations between "people and technology in the full richness of human social and cultural life" (Fruchter et al., 2005). While such priorities are expected for public digital cities, they seem more problematic to ensure for revenue-driven commercial websites. We therefore discuss our application domain

*We thank the City of Luxembourg for their financial support and Leon van der Torre, Matthias Nickles, Joris Hulstijn, Guido Boella, Emil Weydert, Pascal Bouvry, Catherine Pelachaud, Yo Keller and Harko Verhagen. 
based on this distinction. (2) What is social intelligent design applied to digital cities? (3) What are social norms for agents in digital cities? And finally, (4) what is the role of conviviality?

Generally speaking, a convivial place or group is one in which individuals are welcome and feel at ease, but definitions in literature spread from individual freedom realized in personal interdependence, to rational and cooperative behavior, to normative instrument (Caire, 2007b). In the context of digital communities and institutions, such as digital cities, conviviality often refers to qualities such as trust, identity and privacy. One of the European Community 5th framework four themes, Societe de l'Information Conviviale (User-Friendly Information Society, 1998-2002) promoted conviviality through broad projects and initiatives. One example, the Convivio Net Consortium (2003-2005), fostered convivial technologies designed to be people-centered and sought to address growing challenges of digital cities: Bridge increasing digital divides between social groups, remedy nascent social fragmentation and isolation, increase social cohesion, strengthen community identity and support new communication and interaction paradigms.

By means of information and communication technologies, digital cities are virtual presence and extensions of our physical cities. Originally an American phenomenon, digital cities were first supported by the European Community in 1993 with Telecities Network and in 2000, with a 30year plan encouraging member countries to build their own digital cities based on a common vision while following a technological step-by-step approach: Systems interoperability, Intelligent City Systems (2009), Ambient Intelligence (2013) and Smart Cities (2030). We identified two broad categories: Public and commercial digital cities. Whereas main goals of commercial digital cities are to innovate with next generation networks, to create spaces allowing users social information exchanges and to explore vertical markets, for example online shopping and rated services, the principal objectives of public digital cities are to "transform and modernize local administrations in order to improve the level and quality of life of the population at both individual and community levels" (Ishida, 2000), for example, 24/7 online access to municipal services and multilinguism.

The layout is as follows: In Section 2 we contrast digital cities as commercial websites to digital cities as public websites and in Section 3, we compare ergonomics and human factors to intelligent agents. In Section 4, we look at legal norms as opposed to social norms and in Section 5 we analyze social norms for conviviality by contrasting the positive aspects of conviviality to its negative aspects. In section 6 we look at related works and in section 7 , we discuss results and summarize our findings.

\section{Digital Cities: Commercial versus Public Websites}

There are many different types of digital cities and many ways to define them. "They can be seen as a local social information infrastructure, providing information over the real city to locals and of course to visitors of the real city. The digital city can also be approached as a communication medium, influencing the personal networks of inhabitants of a digital neighborhood. Another view is the digital city as a tool to improve local democracy and participation. Finally [...] the digital city can be seen as a practical resource for the organization of every day life. One can think of local electronic commerce, and the provision of online public services as a support of local economic activities. However, the digital city may also become an experiment with new forms of solving problems and coordinating social life. Where currently most activities are coordinated by the market or by the state, the digital city may become a tool that enables people to do things by mobilizing the available local resources, using existing and emerging social networks" Den Besselaar et al. (2000) .

Observing that "Digital cities commonly provide both profit and non-profit services and have a dilemma in balancing the two different types of services", Ishida (2000) raises the question: Can public digital cities compete with commercial ones? (figure 1). Indeed, "without profit services, digital cities become unattractive and fail to become a portal to the city. Without nonprofit services, the city may become too homogeneous like AOL digital cities as a result of pursuing economic efficiency. In any case, digital cities are forced to face competition with private companies, which provide only profit services." 

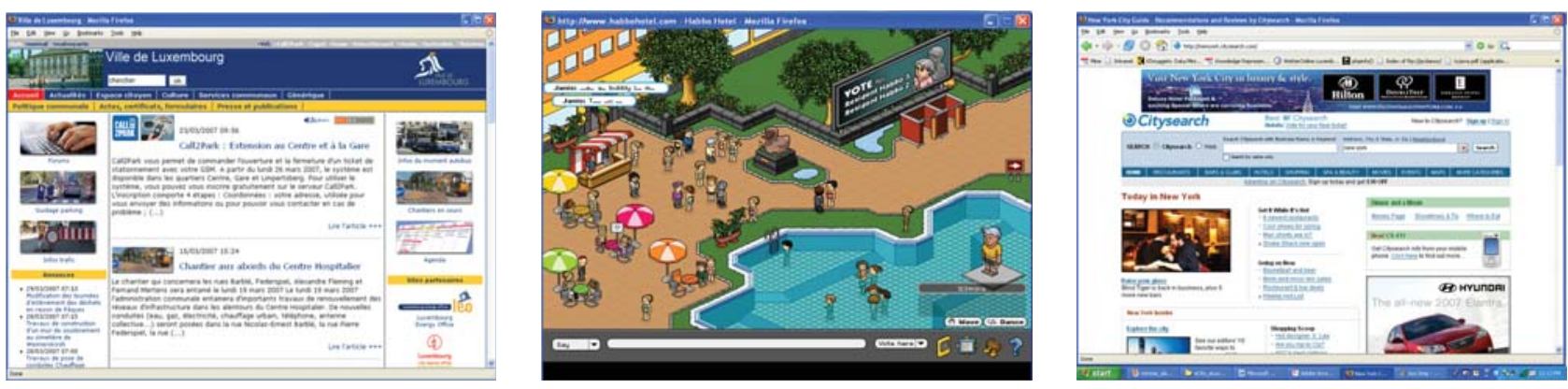

Figure 1: eCity Luxembourg, Habbo Hotel and MSN CitySearch

\subsection{Goals of Digital Cities}

Commercial digital cities as commercial portals started as local portals run by private companies, such as phone, web and airline companies, competing with each other. Nowadays, global companies such as AOL and Microsoft offer city guides with services: Shopping, entertainment, local information and maps. Their business goals are geared toward vertical markets and their revenues are generated by advertising. Their general trend is to provide information that is easy to find and search for, good maintenance of systems and frequent updates. They are effective in Asia, where they complement government agencies, but limited in scope by their top-down controlled and selected content, lack of two-way interaction with users and main purpose, e.g. advertising.

Public digital cities started in the US with American community networks, inspired by a tradition of community-centered, grass-roots engagements that emphasized freedom of speech and activism. Their original goal was to create a virtual information space for example, the WELL Whole Earth'Lectronic Link and Blacksburg Electronic Village.

Case study: Blacksburg Electronic Village (BEV) was built in 91 as a consortium lead by universities, such as Virginia Tech. University, by regional companies such as Bell Atlantic and local authorities. It was a high profile project but with very little community involvement to the vision. It was constructed from a technological point of view and the first project of the kind with web interface. It rapidly grew until 95 then its activity decreased due to fundamental disagreement between all the partners' expectations. The companies looked for revenues elsewhere and universities stopped providing internet to non-university members. Although still active today, BEV has only a very local focus on community use of technology and learning.

US public digital cities main challenges were, first the lack of synergy between community networks, private companies and administrations and second, the competition between profit and non-profit organizations. Today they align with eGovernments. In Europe, public digital cities evolved through the leadership of the European Community, launching first the Telecities program in 93, then large scope programs and projects such as Eurocities, Intelcities and e-Agora. At the European Community level, the goal is to share ideas and technologies between all the cities to strengthen the European partnership. At the level of the cities, the goal is to use information and communication technologies to resolve social, economic and regional development issues and improve the quality of social services. Their characteristics today are to be networks generated within and for specific regions, to form complex communities based on collaborations between citizens, universities, city administrations and private companies, and to emphasize social inclusion. Their main challenge is the difficulty to integrate grass-roots communities and commercial point of views which appears in the relatively slow commercialization of services and information.

\subsection{Technologies and Architectures of Digital Cities}

Commercial digital cities rely on accumulating urban information and are well maintained. They use proprietary systems and count on search engines, that rank interest links by sponsors, for business opportunities. Early on, commercial digital cities recognized the importance of usability and have done well to make their services usable by many. The claim of America Online was: "So 
easy to use, no wonder it's number one". Public digital cities look toward open source systems: Video casts of town meetings, blogs, postings for Virtual Helsinki, multi-user games for Digital Amsterdam. By lack of funds, the sites are not always well maintained, which caused many downfalls such as Digital Amsterdam, Blacksburg (BEV) and Parthenay.

Case study: Amsterdam Digital City (DDS) started in 94 as a grass-roots initiative and evolved into a non-profit organization with government support and the participation of private companies. The goals of Digital Amsterdam were to support community activities and local economy, encourage political discourse by linking citizens to the administration and innovate. Its very successful interface of squares and cafes as well as interactive public debates inspired many other digital cities, among which Digital Bristol. The issues that caused its downfall were persistent technical problems and the initial lack of common understanding and vision between the stakeholders. Digital Amsterdam exploited all the early Internet possibilities such as USENET, IRC, GOPHER, MUDs, MOOs, Telnets and Free-nets.

Public digital cities rely on high speed network tightly coupled with the physical city (Helsinki) and platform for community network. They have multilayer architectures, for example in Digital Kyoto, information layer, interface layer and interaction layer.

Case study: Virtual Helsinki started in 95 as a powerful consortium of Telecom such as Nokia and Elisa, the city of Helsinki, private companies such as IBM and local universities; However, it did not include any grass-roots community nor voluntary services. The goals were: Technological advances with, for instance, the use of ISDN and Video on Demand (95), DSL, Ethernet, ADSL (97), IP based Video conferencing (98), ISDN video telephony, 3-D mapping of Helsinki (99). Digital Helsinki has been highly profitable and socially relevant with citizens' participation and contribution to social cohesion. Its projects of using avatars for citizens inspired the Habbo community.

\subsection{Organizations of Digital Cities}

Commercial digital cities are for-profit whereas public digital cities are non-profit. Public digital cities set up complex consortia with universities and companies that seem easier to manage in the US than in Europe.

Case study: Seattle Community Network (SCN) emerged in 92 as part of the Computer Professionals for Social Responsibilities group's civil activities. It was first hosted on a donated Intel 386 running a donated copy of BSDI UNIX operating system, using FreePort (Cleveland FreeNet text based) user interface software. Lead by citizens, SCN grew in size by cooperating with regional libraries and offering to all free network access and services, such as email and homepage. Due to continuous financial problems and competition with commercial portals, the activity decreased to its current reduced level, mainly to provide free public-access network. Interestingly, among the more recent grass-roots activities is the emergence of the Seattle Community Wireless Network that creates a broadband wireless metropolitan area network.

Asian digital cities, called city informatization, emerged as government initiatives. Their goal is to develop their country through technological innovation. There were attempts to integrate grass-roots activities and university driven projects in 99 with Digital Kyoto and Shanghai but the greatest challenge still remains their top-down approach based on administration activity.

\subsection{SUMmary}

Commercial and public digital cities were originally very different but seem to be more overlapping today. Commercial digital cities tend to depend on business strategies, such as merging, acquisition and delocalization, creating tough competitions for market penetration and users' loyalty for example between MSN Citysearch, AOL City Guide and Yahoo! Local. Public digital cities tend to depend on political agendas to motivate progress for technological and social improvements, for example, Bologna Iperbole, with the impulse of progressive political leadership, innovated in 1994 by setting up open spaces to allow groups of citizens to publish information and engage in debates with public officials, while Issy-les-Moulineaux started, in 1996, to develop its successful one-stop administration, including online live interaction of citizens to town meetings and interactive maps. 
However, as yet, no one model has been identified. In the US for-profit businesses and nonprofit organizations co-exist and compete, in EU the attempts are to coordinate administrations, companies and citizens while Asia pursues government directed growth. Governments' goals for digital cities consist to help close geographic and social digital divides, with access everywhere and for all, to accelerate economic development, and to make the governments of cities more efficient and accessible. Pluralism and participation are combined with multi-disciplinary approaches, synergy between administrations, companies and citizens and, most importantly, a shared vision between all stakeholders.

The success factors of digital cities consist in achieving participation of institutions and communities, in balancing top-down direction, needed for technical infrastructure, and grass-roots initiatives, necessary to insure citizens' cohesion and in finding an equilibrium between economic and civic motivations. Ultimately, digital cities need to deal with the same complexity as real cities to attract and retain usage, and to function as entities that augment their physical counterparts.

\section{Social Intelligent Design for Digital Cities}

"One concept of the digital city is to provide infrastructure for networking local communities and to promote social interaction among people who visit or reside in a city" (Azechi et al., 2000). A number of strategies can be used to meet these goals. Therefore, as "the most profound influence of the social intelligence design approach can be felt in the studies of online communities, where mediated communication is a key vehicle for creating and maintaining social contact" (Fruchter et al., 2005), we will look at intelligent agents approaches and contrast it with ergonomics and human factors approaches.

\subsection{Goals of Ergonomics And Intelligent Agents}

Ergonomics practitioners are concerned with the "capabilities and limitations of humans to improve the design of systems and devices" (Lund et al., 2005): They study how humans behave physically and psychologically in relation to particular environments, products or services; They make suggestions, based on users' reactions and preferences in relation to visual and other sensory stimuli, on how to redesign, for example a website, to meet users' needs or give general guidelines.

In multi-agent systems an agent is defined as "a computer system that is situated in some environment, and that is capable of autonomous action in this environment in order to meet its design objectives [...] Agents are capable of flexible (reactive, proactive, social) behavior" Wooldridge (2004). This capability is crucial for digital cities since it allows agents to cooperate, coordinate their actions and negotiate with each other; It is also fundamental to social intelligence design since "conventionally, social intelligence has been discussed as an ability of an actor/agent to relate to other actors/agents in a society, understand them, and interact effectively with them." (Fruchter et al., 2005). Intelligent agents, with their artificial intelligence capabilities can assist users, act on their behalf, adapt and learn while performing non-repetitive tasks. It is a multi-disciplinary field including for instance, socio-cognitive research, psychology, linguistics and pedagogy.

\subsection{Applichtions for Ergonomics and Intelligent Agents}

With systems becoming increasingly complex and pervasive, trends in ergonomics have been to increase the usability of systems with the design of interfaces that allow users to interact with the systems control commands and mechanisms, in a manner referred to as natural and user-friendly, using menus, icons, keystrokes, mouse clicks, and similar capabilities. This is made possible with the application of engineering psychology, a research branch of psychology theory applied to the design of systems. Ergonomics practitioners develop design specifications, guidelines, methods, and tools to ensure that systems are compatible with the characteristics of humans who operate, maintain or otherwise interact with them. For example, the digital city of Luxembourg, in the process of creating a one-stop administration, chose to start with the declaration of a new born baby, a key procedure for its citizens, and a complex operation for the administration as 
it requires the interoperability of different branches of administrations and services, such as hospital, internal revenue services and social security to create, verify and register the identity for the new born citizen. While performing the required operations online, citizens must seamlessly navigate through all the different environments. Therefore, ergonomics practitioners must ensure that conventions and constraints, such as interoperability or multilinguism are respected and that heuristics and guidelines are followed (Norman, 1999), for example in using templates, Stylesheets and file formats for quick loads as well as non-proprietary software for maintainability.

Intelligent agents systems, however, use of a different branch of psychology, cognitive psychology, "concerned with mental processes (as perception, thinking, learning, and memory) especially with respect to the internal events occurring between sensory stimulation and the overt expression of behavior" (Merriam-Webster, 2006), emphasizing human thinking and processing of information. Intelligent agents such as Embodied Conversational Agents "are autonomous agents with a human-like appearance and communicative skills. They have shown their potential to allow users to interact with the machine in a natural and intuitive manner through human communicative means: the conversation. To be able to engage the user in a conversation and to maintain it, the agents ought to have capabilities such as to perceive and generate verbal and nonverbal behaviors, to show emotional states, to maintain social relationship" (Pelachaud, 2005). For example, the Swedish online Customs Department opted to solve its increasing load in incoming communications, telephone, IM, chat and emails, for its human agents by implementing embodied conversational agents. The result was a $20 \%$ load decrease for incoming communications, $40 \%$ of all requests happening outside office hours and more than 1500 (fifteen hundred) simultaneous dialogs at peak hours. Indeed as demonstrated by Cassell (2000)'s Rea system embodied conversational agent interfaces are "capable of making content-oriented, or propositional, contributions to a conversation with human users".

For Sadek et al. (1997), conversational agents must be endowed with conviviality: An agent is convivial if it is rational and cooperative, and the interaction with the agent is convivial "if the agent presents, jointly and at all times, one or all of the following characteristics: Capacity for negotiation, contextual interpretation, flexibility of the entry language, flexibility of interaction, production of co-operative reactions and finally of adequate response forms." Finally, conviviality, as "the essential and global characteristic of services, emerges from the intelligence of the system and not from a set of local characteristics that vary depending upon the application context and the types of users"; Consequently a list of criteria will by itself not suffice. Additional critical factors to consider are: on the one side, the relations that bind the criteria together and on the other side, the way these relations are perceived by individuals. These communicative capacities and social intelligence based on emotional intelligence are crucial to enhance agents'ability to interact with users.

(Gomes et al., 2004) intelligent tutoring system provides a recommendation service of student tutors for computational learning environments. "Each agent pupil represents a pupil logged onto the system. One of the functions of the system is to be the client for an instant message service. Through its agent pupil, any pupil can communicate with other pupils in the system [...] Another function of the agent pupil is to pass information on the affective states of the pupil. This information can be inferred by the agent or be adjusted by the pupil itself."

The authors' claim is that "convivial social relationships are based on mutual acceptance through interaction" hence on reciprocity and in this case students helping each other. A utility function takes as input a student's social profile and computes the student's affective states indicating if the student needs help; if $\mathrm{s} /$ he does then the system recommends a tutor. Remaining challenges are with defining utility function inputs to compute recommendations, presently a set of random values, and to automate inferences of students requiring help. This exposes the need for further research in evaluation methods and measures for concepts such as mood, sociability and conviviality. Looking at interpersonal factors that have to be taken into account when designing such systems, Heylen et al. (2003) are developing an emotionally intelligent tutor agent that tries "to construct a model of the mental state of the student and is knowledgeable of the potential effects of tutoring acts on the mental state. These insights are used to determine the appropriate action sequence and the manner of executing the actions". 
These critical challenges point out the ethical issues raised by the possible development of such systems: Preserving pupils' privacy, securing the information gathered to create their social profiles, deterring possible misuse of pupils' affective states and system errors concerning the data. They also point out the importance of developing and using guidelines, similarly to the European Privacy Design Guidelines for the Disappearing Computer Lahlou and Jegou (2003) established to "implement privacy within the core of ubiquitous computing systems" Lahlou et al. (2005). A number of research addressing these issues are for example, Erickson and Kellogg (2000) socially translucent systems characterized by visibility, awareness, and accountability or Ter Hofte et al. (2006) study of place-based presence and trust evaluation.

Casare and Sichman (2005) reputation system further illustrates intelligent agents capabilities. Reputation is an "indispensable condition for the social conviviality in human societies", it makes information transparent, as all group members receive the same information about their peers and it ensures conviviality for the group. In this system, everyone is aware of anyone's behavior, that is anyone's compliance or not to the rules of the group. A functional ontology of reputation for multi-agent systems is defined whereby "roles are played by entities involved in reputative processes such as reputation evaluation and reputation propagation."

The authors' claim is that "concepts of the legal world can be used to model the social world, through the extension of the concept of legal rule to social norm and the internalization of social mechanisms in the agent's mind, so far externalized in legal institutions". In their system, the agents actual behaviors are compared to the social norms observed in their world. The process, however, presupposes an initial reputation profile of users that agents can then update in real time. Reputation acts as a communication tool, ensuring complete social transparency throughout the system. The strict application of norms to reputation however may be difficult and suffer from rigidity, and one can wonder about the ethical issues, such as privacy, raised by this type system.

\subsection{Summary}

The recent and large scale development of intelligent interfaces combines computing power, adaptive and dynamic systems for more natural and invisible interactions between users and computers. The ultimate steps still occur at the interface level, between the input and output hardware devices, and the software that determines and presents the information to the user for example, on a screen. As technologies develop and user's expectations grow, the field of human-computer interaction broadens to encompass a greater number and variety of fields that intertwine in more intricate and complex ways such as computer science, psychology, cognitive science, human factors, ergonomics, sociology, and artificial intelligence; All concurring and contributing to the creation and enhancement of optimal and seemless user experiences.

Human computer interaction research now faces new critical challenges Markopoulos et al. (2005): Designing systems and environments that can be perceived as socially intelligent; Designing intelligence that will support human-to-human cooperation and social interactions; Evaluating social intelligence and defining the benefits of social intelligence. Answer to the last question would appear to be a requirement for the evaluation of social intelligence and for designing intelligence that will support social interactions. Therefore, to study social user-interfaces, Markopoulos et al. experiment with their robotic research platform, iCat, for it to exhibit a rich set of humanlike behaviors and conclude that the challenge ahead is "the need to make systems capable of understanding and relating to people at a social level, timing, and cuing their interactions in a socially adept manner".

"A desirable social culture will afford the members of the community to learn from each other" (Fruchter et al., 2005), and to achieve this is among the many challenges social intelligence design aims to address with "methods of establishing the social context, embodied conversational agents, collaboration design, public discourse, theoretical aspects of social intelligence design, and evaluation of social intelligence" Nishida (2001). 


\section{Social Norms and Institutional Norms in Digital Cities}

In their introduction to normative multi-agent systems, Boella et al. give the following definition: "A normative multi-agent system is a multi-agent system together with normative systems in which agents on the one hand can decide whether to follow the explicitly represented norms, and on the other the normative systems specify how and in which extent the agents can modify the norms" (Boella et al., 2006). We first discuss the distinction among various kinds of norms, and then we discuss three issues in this definition, illustrated by examples in digital cities.

\subsection{The Different Kinds of nORMS}

Several kinds of norms are usually distinguished in normative systems. Within the structure of normative multi-agent systems Boella and van der Torre (2004) distinguish "between regulative norms that describe obligations, prohibitions and permissions, and constitutive norms that regulate the creation of institutional facts as well as the modification of the normative system itself". A third kind of norms, procedural norms, can also be distinguished "procedural norms have long been considered a major component of political systems, particularly democratic systems" states Lawrence who further defines procedural norms as "rules governing the way in which political decisions are made; they are not concerned with the content of any decision except one which alters decision-making procedures" (Lawrence, 1976).

Constitutive norms: Boella et al. note several aspects of constitutive norms, one is as intermediate concept exemplified by "X counts as a presiding official in a wedding ceremony", "this bit of paper counts as a five Euro bill" and "this piece of land counts as somebodys private property" (Boella and van der Torre, 2005). Searle further explains that "the institutions of marriage, money, and promising are like the institutions of baseball and chess in that they are systems of such constitutive rules or conventions" (Searle, 1970). In digital cities, examples are the marriage norms and voting in the sense that going through the procedure counts as a vote.

Boella et al further believe that "the role of constitutive rules is not limited to the creation of an activity and the construction of new abstract categories. Constitutive norms specify both the behavior of a system and the evolution of the system [...]" (Boella and van der Torre, 2004). The dynamics of normative systems is here emphasized as in norms revision, certain actions count as adding new norms for instance amendments: "The normative system must specify how the normative system itself can be changed by introducing new regulative norms and new institutional categories, and specify by whom the changes can be done" (Boella and van der Torre, 2004). Today "US government agencies are required to invite public comment on proposed rules" (Lau et al., 2005). This is done through the digital city government interface that allows revisions to be traced.

Two other aspects of constitutive norms are organizational and structural, that is, how roles define power and responsibilities and how various hierarchies structure groups and individuals. "Not only new norms are introduced by the agents playing a legislative role, but also that ordinary agents create new obligations, prohibitions and permissions concerning specific agents" (Boella and van der Torre, 2004).

Regulative Norms: "Regulative norms are not categorical, but conditional: they specify all their applicability conditions" state Boella and van der Torre (2004); The authors further add that "legal systems are often modeled using regulative norms, like obligations and permissions. However, a large part of the legal code does not contain prohibitions and permissions, but definitions for classifying the commonsense world under legal categories, like contract, money, property, marriage. Regulative norms can refer to this legal classification of reality" (Boella and van der Torre, 2005). Regulative norms express constraints, obligations and prohibition for example, citizens using the Luxembourg digital city website, must use the file format PDF, rather than postscript, to access the administration documents. Regulative norms also express permission, rights and powers, for example access rights and voting rights, if you are resident for more than 5 years or born in the city of Luxembourg. Another example is for creating an online library account on Paris digital city website, a parents' authorization is necessary if you are under 18 years old, while an example of social regulative norm is, for instance, that it is forbidden to use bad language on public digital city forum. 
Procedural norms: Lawrence distinguishes two kinds of procedural norms "objective procedural norms are rules which describe how decisions are actually made in a political system; a system's objective procedural norms are a primary determinant of the content of political decisions in that they specify who actually makes decisions, who can try to influence decision makers, what political resources are legitimate and how resources may be used. Subjective procedural norms, on the other hand, are attitudes about the way in which decisions should be made" (Lawrence, 1976). Procedural norms are instrumental for individuals working in a system. In digital cities, examples are back office procedures and in the previous example of a citizen using bad language in a public forum, then the other citizens' reactions to all send rebuffs.

\subsection{Explicit versus Implicit Representation of Norms}

The first property of norms in the definition of normative multi-agent systems is that norms are explicitly represented. Norms are often given as requirements of computer systems but only implicitly represented. An example of implicit representation is a form in which you would be asked to state whether or not you keep a pet at home without mentioning to you the purpose of the information e.g. that if your answer is affirmative, either you will be requested to pay a license fee or the amount of the fee will be directly deducted from your bank account. Implicit representations are opaque to users and prevent governments to fulfill the democratic promise that transparency and explicit representations deliver. As users' need for explanation and understanding of rules and regulations grows, representations have to become more explicit and personalized to their expectations. Similarly, governments' interest also reside in the explicit representation of norms that can be addressed through the development of mechanisms for knowledge representation and reasoning.

Current efforts are somewhat in-between implicit and explicit representation with tools for text representation and retrieval with more advanced ontologies, semantic links and search capabilities. To this effect, the US government launched in 2006 a business portal to help small businesses comply with Federal regulations, a need that was not being met by any other Federal government program. (Caire, 2007c) In NYC, for instance, to renew online your Driver's License the stipulation is: "You cannot change your address during this transaction. You must have a completed form MV-619 (Eye Test Report) for this transaction. Read the requirements before you begin this transaction".

Norms for conviviality are social norms, and even though they can be communicated, they are often not made explicit. Consider for example the norm of being politically correct: An agent may appear to follow and embrace the beliefs of a group by fear of appearing different but without conviction, following a group without truly being part of it. Explicit norms relevant to conviviality may refer to the cooperative behavior of agents.

\subsection{The Violation of Norms}

The second property in the definition of normative multi-agent systems is that norms can be violated. This is also seen as an important condition for the use of deontic logic in computer science: "Importantly, the norms allow for the possibility that actual behavior may at times deviate from the ideal, i.e. that violations of obligations, or of agents rights, may occur", as observed by Jones and Carmo (2002).

If norms cannot be violated then the norms are regimented. For example, if there is a norm in access control that a service can only be accessed with some certificate, then this norm can be implemented in the system by ensuring that the service can only be accessed when the certificate is presented too. Regimented norms correspond to preventative control, in the sense that norm violations are prevented. When norm violations are possible there is only detective control, in the sense that behavior must be monitored, and norm violations have to be detected and sanctioned. "Social order requires social control, an incessant local (micro) activity of its units, aimed at restoring the regularities prescribed by norms. Thus, the agents attribute to the normative system, besides goals, also the ability to autonomously enforce the conformity of the agents to the norms, because a dynamic social order requires a continuous activity for ensuring that the normative 
systems goals are achieved. To achieve the normative goal the normative system forms the subgoals to consider as a violation the behavior not conform to it and to sanction violations" (Boella and van der Torre, 2005).

Norms can be violated because they are soft constraints. In digital cities, disincentives are often the mechanism used to prevent users from infringing their norms. For example, if you don't have a valid registration sticker on your windshield you may be ticketed, if you do illegal dumping you will be fined or if you are a malicious intruder in a digital city you will be prosecuted. When norm violations are possible, there are normative multi-agent systems in which the violations can trigger new obligations, the so-called contrary-to-duty obligations. With contrary-to-duty obligations, there is not only a distinction between ideal and bad behavior, but there is also a distinction between various degrees of sub-ideal behaviors. Norm violations can also lead to sanctions for compensation or attempts to undo the violation, such as the roll-back operation in database systems. When there is a sanction, the repair action can either be completely undone, as for example in business or economics, or we can remain in sub-ideal state, as in some kind of moral reasoning.

There are many examples of conviviality violations: Ignoring cultural and social diversity is violating conviviality as it creates conviviality for a group at the expense of others. Another example of conviviality violation is if a citizen is being ignored when coming to ask advices to a city administrator: The online Paris library insures kind and pleasant service to members and proposes a free mediator service in case of difficulties dealing with city clerks. Promoting exclusion, intolerance and deception can be considered violation of conviviality norms.

\subsection{SUMMARY}

The role of norms for conviviality in digital cities is to reinforce social cohesion by reflecting the group's core values internally as well as externally. By making rules explicit, conviviality contributes to reduce conflicts, optimize members' performances within communities as well as between communities and improve coordination throughout. Moreover, social warranty and protection mechanisms are achieved through praise and encouragements toward members who conform to the rules, and anger and blame toward the ones who do not. Moreover, there are many possible approaches to address violations of conviviality: Enforcing values such as sharing knowledge and skills, equality or trust. In an overall computing environment, focus must be on people and their social situations (Stephanidis, 2006), therefore, social norms and their violations must be taken into account. By reinforcing common shared ground between the members of a group, conviviality facilitates the auto-regulation mechanisms that digital cities seek for as protection barriers for their members and citizens.

\section{The Role of Conviviality}

Table 1: Definitions of conviviality

\begin{tabular}{|l|}
\hline Etymological and Domain Specific Definitions of Conviviality \\
\hline Origin: 15th century "convivial", from latin, convivere "to live together with, to \\
eat together with". (French Academy Dictionary) \\
\hline Adj. Convivial: (of an atmosphere, society, relations or event) friendly and lively, \\
(of a person) cheerfully sociable. (English Oxford Dictionary) \\
\hline Technology: Quality pertaining to a software or hardware easy and pleasant to \\
use and understand even for a beginner.(Adj.) User friendly, (Noun) Usability. By \\
extension also reliable and efficient. (Grand Dictionnaire Terminologique) \\
\hline $\begin{array}{l}\text { Sociology: Set of positive relations between the people and the groups that form a } \\
\text { society, with an emphasis on community life and equality rather than hierarchical } \\
\text { functions. (Grand Dictionnaire Terminologique) }\end{array}$ \\
\hline
\end{tabular}


Looking at some definitions shows that the meaning of conviviality depends on the context of use (table 1): In sociology, conviviality typically describes a relation between individuals and emphasizes values such as equality and community life. In technology however, convivial typically describes a relation between a software and a user and emphasizes qualities such as user-friendly, efficient and reliable.

A less common view of conviviality emerges when it becomes an instrument to exercise power and enforce one point of view over another Taylor (2004). Conviviality is then experienced as a negative force by the loosing side. We summarized, from different sources, positive and negative aspects of conviviality and present, as examples, some excerpts (table 2): The emphasis is on sharing of common grounds and inclusiveness for positive side, on division and coercive behaviors for negative side.

Table 2: The different aspects of conviviality

\begin{tabular}{|c|c|c|}
\hline $\begin{array}{c}\text { Positive aspects } \\
\text { (Enabler) }\end{array}$ & $\begin{array}{c}\text { Grey aspects } \\
\text { (Ignorance) }\end{array}$ & $\begin{array}{c}\text { Negative aspects } \\
\text { (Threat) }\end{array}$ \\
\hline Share knowledge \& skills & Ignore cultural diversity & Crush outsiders \\
\hline Deal with conflict & Hide conflict & Fragmentation \\
\hline Feeling of "togetherness" & Promote homogenization & Totalitarism \\
\hline Equality & Political correctness & Reductionism \\
\hline Trust & Non-transparent systematic controls & Deception \\
\hline
\end{tabular}

\subsection{From Individuals to Groups}

Being the first in 1964 to use conviviality in a scientific and philosophical context, Polanyi (1974) describes it as synonymous with empathy: It allows individuals to identify with each other thereby experiencing each other's feelings, thoughts and attitudes. By extension, a community is convivial when it aims at sharing knowledge: Members trust each other, share commitments and interests and make mutual efforts to build conviviality and preserve it. Illich (1971) also describes a convivial learning experience as based on role swapping, teacher role alternating with learner role; He emphasizes the concept of reciprocity as key component to conviviality and creates the concepts such as the learning webs, skill exchange networks and peer-matching communication, later expanded by Papert and the Constructionists, with a number of ideas for instance the learning-by-making (Papert and Harel, 1991).

But conviviality is also a social form of human interaction, says Schechter (2004). Linking interaction to physical experience she recognizes the social dimension of conviviality, as a way to reinforce group cohesion through the recognition of common values. "Thus the sharing of a certain kind of food and/or drink can be seen as a way to create and reinforce a societal group through a positive feeling of togetherness (being included in/or part of the group), on which the community's awareness of its identity is based." Physical experiences of conviviality are transformed into learning and knowledge sharing experiences: "To know is to understand in a certain manner that can be shared by others who form with you a community of understanding".

However, Ashby (2004) points out the instrumentalization of conviviality when one group is favored at the expense of another, "truth realities about minorities are built from the perspective of the majority via template token instances in which conflict is highlighted and resolution is achieved through minority assimilation to majority norms [...] Conviviality is achieved for the majority, but only through a process by which non-conviviality is reinforced for the minority".

\subsection{From Groups to Institutions}

For Illich (1974), conviviality signifies "individual freedom realized in personal interdependence"; It is the foundation for a new society, one that gives its members the means, referred to as tools, for achieving their personal goals: "A convivial society would be the result of social arrangements that 
guarantee for each member the most ample and free access to the tools of the community and limit this freedom only in favor of another member's equal freedom". In (Putnam, 2000), conviviality is considered as an enhancement to social capital and seen as a condition for a civil society, one in which "communities are characterized by political equality, civic engagement, solidarity, trust, tolerance and strong associative life"; While, according to Lamizet (2004), conviviality describes both "institutional structures that facilitate social relations and technological processes that are easy to control and pleasurable to use". (Taylor, 2004), however, argues that "Conviviality masks the power relationships and social structures that govern communities". She further explores the contradiction between institution and conviviality, questioning "whether it is possible for convivial institutions to exist, other than by simply creating another set of power relationships and social orders that, during the moment of involvement, appear to allow free rein to individual expression [...] Community members may experience a sense of conviviality which is deceptive and which disappears as soon as the members return to the alienation of their fragmented lives".

\subsection{SUMMARY}

On one hand conviviality allows individual expression while, on the other hand, contributing to the standardization and uniformization of representation systems. No one has considered the range of safeguards needed to protect individuals. The negative sides of conviviality, reveal mechanisms that indicate pitfalls and point toward the safeguards needed to protect individuals, groups and institutions. For digital cities, such issues raise ethical questions that must be addressed with, for example, the set up of guidelines and best practices to enforce the inclusion of all groups' points of view. It is worth noting that the positive sides of conviviality contribute to promote values such as social cohesion, inclusiveness and participation, all coinciding with social intelligence values, and can therefore genuinely benefit from social intelligence design approach.

\section{RELATED WORKS}

The goal, to design interfaces that are closer to the way human think than the way machine operate, raises questions such as: "What is, at this very moment, the user's state? What does s/he want, like, need, wish? Is s/he alone, at home, in family, with friends, at work (Gross, 2001)? In the context of such spontaneous interactions, innovative approaches based on dynamic notions such as conviviality, trust and behavior are required. Furthermore, in the area of the disappearing computer, "the shift from information worlds to experience worlds" (Streitz et al., 2005) is particularly significant (Caire, 2007a). As stated by de Ruyter and Aarts, user experience for ambient intelligence must be based on: "(i) safeguarding the privacy of the home environment, (ii) minimizing the shift of user attention away from the actual content being consumed and (iii) creating the feeling of being connected when consuming content over different locations" de Ruyter and Aarts (2004).

In a rather new area of research called mixed-initiative interaction "people and computers take initiatives to contribute to solving a problem, achieving a goal, or coming to a joint understanding" (Horvitz et al., 2004). A critical element is how users focus their attention: "Attentional cues are central in decisions about when to initiate or to make an effective contribution to a conversation or project" (Horvitz et al., 2003). Mixed-initiative research aims at developing software that filters appropriately incoming information to shield users from incoming disturbances such as emails and phone calls. The filtering of incoming information is achieved through measuring user's keystrokes and scrolling activities, recording the number of opened windows, analyzing content, checking events in calendars, location and time of day and so on.

The Companions that Wilks (2004) envisions are persistent software agents attached to single users. They act as intermediaries for all information sources that users cannot manage. For instance, Companions for seniors provide company to senior citizens and they act as technical task assistant to search the web for travels or keep track of the events their owners forget. Conversely, Companions for juniors provide assistance with teaching, explanations-on-demand and advices. 


\section{Conclusion}

In this paper we consider the use of social intelligence design to model conviviality for digital cities. We look at the following issues: First, we distinguish commercial digital cities from public digital cities and note some complex overlaps. Second, as ergonomics has become an integrated part of design, intelligent agents are key to the development of conviviality. Third, the kinds of norms typically distinguished in legal systems can be distinguished for norms of conviviality too. Fourth, the issue of negative sides of conviviality and ways to deal with it is of central concern in web communities like digital cities. Fifth, the role of conviviality as a mechanism to reinforce social cohesion and as a tool to reduce mis-coordination in digital cities can be facilitated with a social intelligence design approach.

Moreover, we note that intelligent interfaces allow instant interactions and thereby create strong needs for coordination and regulation mechanisms. These needs have to be addressed to ensure the safeguard of individuals against abuses, such as privacy intrusions and identity manipulations. Therefore, it is crucial to build into the application designs of digital cities, the necessary protection mechanisms against the potential negative sides of conviviality, such as deception, group fragmentation and reductionism. Best practices and guidelines for designing social intelligence systems, must include aspects such as ensuring all party's points of view, in order to avoid the crushing of one side by another. The concept of conviviality allows to take into account social and cognitive factors as well as ethical issues raised by large scale development of digital cities, it also points out the negative sides to be prevailed over.

From individual social assistants to communication facilitators, numerous research directions in social intelligence design exemplify the need for cognitive and social input to address issues as wide apart as information clutter and digital divide. We believe conviviality to be a crucial coordination and regulation mechanism for digital cities. We therefore emphasize the role of social intelligence to design convivial digital cities.

\section{REFERENCES}

Ashby, W. (2004). Unmasking narrative: A semiotic perspective on the conviviality/nonconviviality dichotomy in storytelling about the german other. Trans, Internet journal for cultural sciences, 1(15).

Azechi, S., Fujihara, N., Sumi, K., Hirata, T., Yano, H., and Nishida, T. (2000). Public opinion channel: A challenge for interactive community broadcasting. In Ishida and Isbister (2000), pages $427-441$.

Boella, G., van der Torre, L., and Verhagen, H. (2006). Introduction to normative multiagent systems. Computational \& Mathematical Organization Theory, 12(2-3):71-79.

Boella, G. and van der Torre, L. W. N. (2004). Regulative and constitutive norms in normative multiagent systems. In Dubois, D., Welty, C. A., and Williams, M.-A., editors, Knowledge Representation, pages 255-266. AAAI Press.

Boella, G. and van der Torre, L. W. N. (2005). Constitutive norms in the design of normative multiagent systems. In Toni, F. and Torroni, P., editors, CLIMA VI, volume 3900 of Lecture Notes in Computer Science, pages 303-319. Springer.

Caire, P. (2007a). Conviviality for ambient intelligence. In Proceedings of Artificial Societies for Ambient Intelligence, Artificial Intelligence and Simulation of Behaviour (AISB'07), pages $14-19$.

Caire, P. (2007b). A critical discussion on the use of the notion of conviviality for digital cities. In Proceedings of Web Communities 200\%, pages 193-200.

Caire, P. (2007c). A normative multi-agent systems approach to the use of conviviality for digital cities. In Boella, G., van der Torre, L., and Verhagen, H., editors, Normative Multi-agent 
Systems, number 07122 in Dagstuhl Seminar Proceedings. Internationales Begegnungs- und Forschungszentrum fuer Informatik (IBFI), Schloss Dagstuhl, Germany.

Casare, S. and Sichman, J. (2005). Towards a functional ontology of reputation. In AAMAS '05: Proceedings of the fourth international joint conference on Autonomous agents and multiagent systems, pages 505-511, New York, NY, USA. ACM Press.

Cassell, J. (2000). Embodied conversational interface agents. Commun. ACM, 43(4):70-78.

de Ruyter, B. and Aarts, E. (2004). Ambient intelligence: visualizing the future. In AVI '04: Proceedings of the working conference on Advanced visual interfaces, pages 203-208, New York, NY, USA. ACM Press.

Den Besselaar, P. V., Melis, I., and Beckers, D. (2000). Digital cities: Organization, content, and use. In Ishida and Isbister (2000), pages 18-32.

Erickson, T. and Kellogg, W. A. (2000). Social translucence: an approach to designing systems that support social processes. ACM Trans. Comput.-Hum. Interact., 7(1):59-83.

Fruchter, R., Nishida, T., and Rosenberg, D. (2005). Understanding mediated communication: the social intelligence design (SID) approach. AI Soc., 19(1):1-7.

Gomes, E. R., Boff, E., and Vicari, R. M. (2004). Social, affective and pedagogical agents for the recommendation of student tutors. In Proceedings of Intelligent Tutoring Systems 2004.

Gross, T. (2001). Ambient interfaces for distributed work groups. ERCIM News, Ambient Intelligence(47).

Heylen, D., Nijholt, A., op den Akker, R., and Vissers, M. (2003). Socially intelligent tutor agents. In Rist, T., Aylett, R., Ballin, D., and Rickel, J., editors, IVA, volume 2792 of Lecture Notes in Computer Science, pages 341-347. Springer.

Horvitz, E., Kadie, C. M., Paek, T., and Hovel, D. (2003). Models of attention in computing and communication: from principles to applications. Commun. ACM, 46(3):52-59.

Horvitz, E., Koch, P., and Apacible, J. (2004). Busybody: creating and fielding personalized models of the cost of interruption. In Herbsleb, J. D. and Olson, G. M., editors, Computer Supported Cooperative Work, pages 507-510. ACM.

Illich, I. (1971). Deschooling Society. Marion Boyars Publishers, Ltd.

Illich, I. (1974). Tools for Conviviality. Marion Boyars Publishers.

Ishida, T. (2000). Understanding digital cities. In Ishida and Isbister (2000), pages 7-17.

Ishida, T. and Isbister, K., editors (2000). Digital Cities, Technologies, Experiences, and Future Perspectives [the book is based on an international symposium held in Kyoto, Japan, in September 1999], volume 1765 of Lecture Notes in Computer Science. Springer.

Jones, A. and Carmo, J. (2002). Deontic logic and contrary-to-duties, pages 265-344. Handbook of Philosophical Logic. Kluwer Academic Publishers.

Lahlou, S. and Jegou, F. (2003). European disappearing computer privacy design guidelines v1.0. Ambient agoras report d15.4., Disappearing Computer Initiative.

Lahlou, S., Langheinrich, M., and Roecker, C. (2005). Privacy and trust issues with invisible computers. Commun. ACM, 48(3):59-60.

Lamizet, B. (2004). Culture - commonness of the common? Trans, Internet journal for cultural sciences, $1(15)$. 
Lau, G. T., Law, K. H., and Wiederhold, G. (2005). Analyzing government regulations using structural and domain information. IEEE Computer, 38(12):70-76.

Lawrence, D. G. (1976). Procedural norms and tolerance: A reassessment. The American Political Science Review.

Lund, A. M., Strother, L., and Rogers, W. A. (2005). The human factors and ergonomics society perspective. In CHI '05: CHI '05 extended abstracts on Human factors in computing systems, pages 1091-1092, New York, NY, USA. ACM Press.

Markopoulos, P., de Ruyter, B., Privender, S., and van Breemen, A. (2005). Case study: bringing social intelligence into home dialogue systems. Interactions, 12(4):37-44.

Merriam-Webster, I. (2006). Merriam Webster OnLine Dictionary. Merriam-Webster.

Nishida, T. (2001). Social intelligence design - an overview. In Terano, T., Nishida, T., Namatame, A., Tsumoto, S., Ohsawa, Y., and Washio, T., editors, JSAI Workshops, volume 2253 of Lecture Notes in Computer Science, pages 3-10. Springer.

Norman, D. A. (1999). Affordance, conventions, and design. Interactions, 6(3):38-43.

Papert, S. and Harel, I. (1991). Constructionism, chapter 1. Cambridge, MA: MIT Press.

Pelachaud, C. (2005). Multimodal expressive embodied conversational agents. In Zhang, H., Chua, T.-S., Steinmetz, R., Kankanhalli, M. S., and Wilcox, L., editors, ACM Multimedia, pages $683-689$. ACM.

Polanyi, M. (1974). Personal Knowledge : Towards a Post-Critical Philosophy. University Of Chicago Press.

Putnam, R. D. (2000). Bowling alone: the collapse and revival of american community. In Computer Supported Cooperative Work, page 357.

Sadek, M. D., Bretier, P., and Panaget, E. (1997). ARTIMIS: Natural dialogue meets rational agency. In International Joint Conferences on Artificial Intelligence (2), pages 1030-1035.

Schechter, M. (2004). Conviviality, gender and love stories: Plato's symposium and isak dinesen's (k. Blixen's) babette's feast. Trans, Internet journal for cultural sciences, 1(15).

Searle, J. R. (1970). Speech Acts: An Essay in the Philosophy of Language. Cambridge University Press.

Stephanidis, C. (2006). A european ambient intelligence research facility at ics-forth. ERCIM News, Embedded Intelligence(67).

Streitz, N., Magerkurth, C., Prante, T., and Roecker, C. (2005). From information design to experience design: smart artefacts and the disappearing computer. Interactions, 12(4):21-25.

Taylor, M. (2004). Oh no it isn't: Audience participation and community identity. Trans, Internet journal for cultural sciences, 1(15).

Ter Hofte, G. H., Mulder, I., and Verwijs, C. (2006). Close encounters of the virtual kind: a study on place-based presence. AI Soc., 20(2):151-168.

Wilks, Y. (2004). Artificial companions. In Bengio, S. and Bourlard, H., editors, Machine Learning for Multimodal Interaction, volume 3361 of Lecture Notes in Computer Science, pages 36-45. Springer.

Wooldridge, M. (2004). An introduction to multi-agent systems. J. Artificial Societies and Social Simulation, 7(3):16-23. 